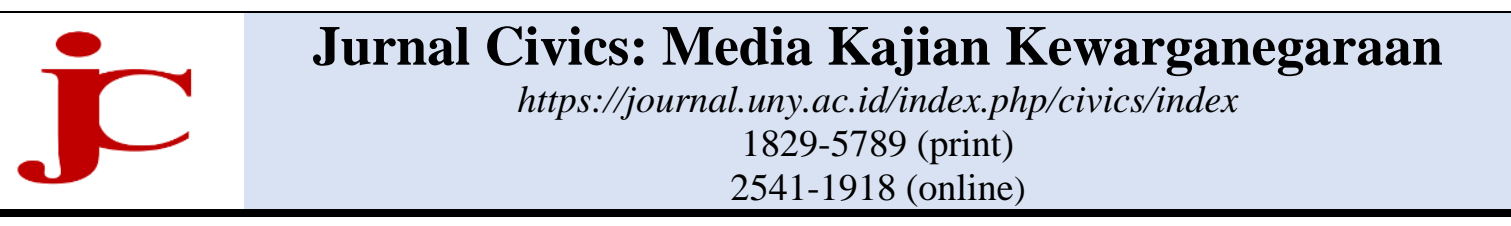

\title{
Penguatan nilai-nilai pancasila di sekolah dasar
}

\author{
Triyanto $^{\text {a, }}{ }^{*}$, Nur Fadhilah ${ }^{\text {b, } 2}$
}

a Program Studi Pendidikan Pancasila dan Kewarganegaraan, FKIP, Universitas Sebelas Maret, Surakarta, Indonesia

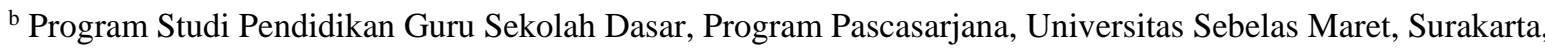
Indonesia

${ }^{1}$ try_uns@yahoo.com $* ; 2$ nurfadhilah795@gmail.com

*korespondensi penulis

\begin{tabular}{ll}
\hline \multicolumn{2}{l}{ Informasi artikel } \\
\hline Sejarah artikel: & \\
Diterima & $: 02-08-2018$ \\
Revisi & $: 29-08-2018$ \\
Dipublikasikan & $: 31-10-2018$ \\
\hline
\end{tabular}

Kata kunci:

nilai Pancasila

sekolah dasar

sosial budaya \begin{abstract}
ABSTRAK
Penelitian ini didasarkan pada pentingnya penguatan nilai Pancasila pada peserta didik di era digital saat ini. Tujuan penelitian ini adalah untuk mengetahui: 1) Bagaimana penguatan nilai-nilai Pancasila di SD; 2) Apa saja kendala untuk memperkuat nilai-nilai Pancasila di SD. Penelitian ini menggunakan penelitian kualitatif. Data dikumpulkan melalui studi pustaka, observasi dan wawancara. Subjek penelitian adalah kepala sekolah, guru, siswa. Hasil penelitian menunjukkan bahwa: 1) Pelaksanaan penguatan nilai-nilai Pancasila di SD termasuk dalam jalur sosialisasi Pancasila melalui pengembangan sosial budaya yang dilakukan melalui salat berjamaah, pemilihan ketua kelas, diskusi kelompok kecil, pramuka, pembelajaran di kelas, jumat bersih, upacara bendera dan piket kelas. Pelaksanaan penguatan nilai-nilai Pancasila di sekolah dasar menemui kendala yaitu sikap anak yang sulit dinasihati dan memiliki kebiasaan di luar sekolah yang kurang baik. Terdapat perubahan sikap dari anti sosial menjadi sikap peduli sosial. Hal ini sangat penting untuk menguatkan nilai-nilai Pancasila.
\end{abstract}

\section{Keywords:}

Pancasila value

elementary school

socio-cultural

\begin{abstract}
This research is based on the importance of strengthening the value of Pancasila in the students in the digital era today. The purpose of this research is to know: 1) How to strengthen the values of Pancasila in elementary school; 2) What are the constraints to strengthen the values of Pancasila in elementary school. This study uses qualitative research. Data were collected through literature study, observation and interview. The research subjects were the principal, teacher, student. The results of the research indicate that: 1) The implementation of Pancasila values in elementary school is included in the socialization of Pancasila through psycho-pedagogical development that consists of congregational prayer, class election, small group discussion, clean Friday, flag ceremony, and class picket. The implementation of strengthening Pancasila values in elementary schools encountered obstacles, namely the attitude of children who were difficult to advise and had bad habits outside of school. There is a change of attitude from anti-social to social care attitude. It is very important to strengthen the values of Pancasila.
\end{abstract}

\section{Pendahuluan}

Era digital adalah kehidupan dimana manusia menggunakan teknologi dalam sebagian besar pemenuhan kebutuhannya. Era digital terlahir dengan kemunculan digital, jaringan internet khususnya teknologi informasi komputer, seperti media sosial yang berkembang saat ini misalnya Twitter dan
Blog (Novak, Razzouk, \& Johnson, 2012; Setiawan, 2017). Meluasnya teknologi ini juga mempengaruhi pembelajaran di setiap jenjang, termasuk sekolah dasar. Media sosial digambarkan sebagai saluran yang digunakan untuk mentransmisikan pengetahuan antara komunitas dan pemelajar (Al-Rahmi \& Zeki, 2017). Beberapa penelitian seperti Larusson 
\& Alterman (2009) dan Ertmer et al. (2011) mengenai dampak positif penggunaan media sosial dalam proses pembelajaran, bahkan Junco, Heibergert, \& Loken (2013) pernah melakukan beberapa media sosial untuk ujian.

Tingginya penggunaan media sosial seharusnya mampu meningkatkan perilaku pro sosial karena media sosial sangat bermanfaat sebagai salah satu sarana untuk berinteraksi. Namun demikian media sosial justru menimbulkan perilaku anti sosial di kalangan masyarakat. Media sosial telah mengubah generasi yang ada pada saat ini menjadi generasi yang paling anti sosial (Amedie, 2015). Kemunculan situs jejaring sosial menyebabkan interaksi interpersonal secara tatap muka cenderung menurun sehingga orang lebih memilih untuk menggunakan situs jejaring sosial karena lebih praktis (Aljawiy \& Muklason, 2011). Perilaku anti sosial bisa melunturkan nilainilai Pancasila sehingga diperlukan penguatan dengan memanfaatkan fungsi Pancasila dalam menghadapi dampak globalisasi tersebut. Pancasila akan mampu menyaring hal yang baik akibat globalisasi (Yudhanegara, 2015). Sitorus (2016:700) mengemukakan bahwa "Pancasila sebagai dasar kehidupan sosial untuk membangun warga negara yang humanis". Pancasila mulai dari sila pertama sampai sila terakhir saling berkaitan, dan sila pertama sebagai dasarnya agar dapat terlaksananya sila-sila berikutnya. sila tersebut adalah: 1) Ketuhanan yang Maha Esa, 2) Kemanusiaan yang adil dan beradab, 3) Persatuan Indonesia, 4) kerakyatan yang dipimpin oleh hikmat kebijaksanaan dalam permusyawaratan perwakilan, 5) Keadilan sosial bagi seluruh rakyat Indonesia. Dari kelima sila tersebut tercermin beberapa nilai secara berturut-turut, yakni ketuhanan, kemanusiaan, persatuan, demokrasi dan keadilan.

Banyak cara untuk menguatkan nilai-nilai Pancasila. Dalam praktik keseharian kehidupan masyarakat terkait dengan nilainilai Pancasila. Penguatan nilai-nilai Pancasila tidak terlepas dari partisipasi siswa sebagai bagian dari warga negara. Dalam penelitian ini dikhususkan pada siswa sekolah dasar. Siswa sekolah dasar umumnya berusia antara 7 sampai 12 tahun yang merupakan masa sangat penting untuk mengembangkan individu sebagaimana yang dibutuhkan masyarakat (Kus, 2015). Dalam hal ini, mengembangkan siswanya dalam kehidupan bermasyarakat yang sesuai dengan nilai-nilai Pancasila. Karakter-karakter siswa pada sekolah dasar dapat dijadikan sebagai acuan dalam proses penyusunan media dalam penguatan nilai-nilai Pancasila yang akan dilakukan, karena menurut Mares, Sivakumar, \& Stephenson (2015), media yang baik adalah media yang sesuai dengan usia siswa.

Tujuan penelitian ini adalah untuk mengetahui penguatan nilai-nilai Pancasila pada salah satu SD di Kabupaten Kebumen dan mengetahui kendala dalam proses penguatan. Hasil penelitian ini diharapkan dapat memberikan manfaat untuk beberapa kalangan baik manfaat secara teoretis maupun secara praktis. Secara teoretis, penelitian ini diharapkan dapat mendukung teori rekayasa sosial yang intinya diperlukan perubahan sikap dan nilai-nilai individu untuk mengatasi suatu masalah. Secara praktis bagi penulis, pembaca, masyarakat dan mata pelajaran PPKn penelitian ini akan digunakan untuk menambah ilmu dan pengetahuan untuk memahami tentang penguatan nilai-nilai Pancasila sebagai dasar negara agar kembali diperkuat sebagai rujukan dalam kehidupan berbangsa dan bernegara.

\section{Metode}

Penelitian ini menggunakan pendekatan kualitatif pada salah satu SD di Kabupaten Kebumen yang telah menerapkan kurikulum 2013, dimana pada kurikulum tersebut lebih menekankan pada aspek afektif. Narasumber pada penelitian ini adalah kepala SD selaku pengawas kegiatan di sekolah, guru kelas I-VI SD selaku pemegang wewenang tertinggi pada kelas tersebut dan mengetahui karakter setiap siswa di tiap kelas mereka, dan sampel siswa kelas I-VI SD dari 156 siswa. Teknik pengumpulan data pada penelitian ini adalah wawancara semi terstruktur kepada kepala sekolah dan guru pada tiap SD serta beberapa siswa kelas I-VI. Apabila respons dari narasumber ada yang dirasa perlu ditanyakan peneliti maka peneliti bisa menanyakan 
kepada responden walaupun di dalam pedoman wawancara tidak ada pertanyaannya. Wawancara kepada kepala sekolah guna menggali informasi tentang kegiatan di sekolah baik kegiatan intrakurikuler maupun ekstrakurikuler dan proses mengajar guru kelas. Wawancara kepada guru kelas guna menggali informasi tentang strategi dalam menguatkan nilai-nilai pancasila di dalam maupun di luar pembelajaran. Sampel siswa kelas I-VI yang representatif pada tiap SD guna menggali informasi tentang kegiatan apa saja yang pernah diikuti siswa selain pembelajaran terkait dengan penguatan nilai-nilai Pancasila. Teknik pengumpulan data yang kedua adalah observasi partisipasi pasif pada guru dan siswa SD, yakni peneliti mengamati langsung kegiatan di dalam kelas dan di luar kelas namun tidak turut campur dalam kegiatan pembelajaran, dan didukung dengan analisis dokumen yang berupa silabus, RPP, buku sumber materi belajar siswa.

Validitas data pada penelitian ini menggunakan triangulasi sumber dan triangulasi teknik karena untuk menutup kemungkinan apabila ada kekurangan data dari salah satu sumber atau salah satu metode, maka dapat dilengkapi dengan data dari sumber atau metode lain. Analisis data pada penelitian ini berlangsung selama proses pengumpulan data dan setelah selesai pengumpulan data yang menggunakan teknik dari Miles dan Huberman mulai dari aktivitas data reduction, data display, dan conclusion drawing/verification (1992).

\section{Hasil dan Pembahasan}

Pengembangan pelaksanaan sosialisasi Pancasila dapat dilakukan melalui pengembangan pendidikan pembelajaran, pengembangan sosial budaya. dan pengembangan melalui kekuasaan (Budimansyah, 2010). Penguatan nilai-nilai Pancasila di sekolah dasar termasuk dalam jalur pendidikan pembelajaran (psycopedagogial development) karena kegiatan yang dilakukan di sekolah dasar tidak terlepas dari kegiatan pembelajaran yang menyangkut tiga aspek, yakni kognitif, afektif dan psikomotor. Sesuai dengan Kozhanova,
Svechnikova, \& Guliya (2017), dalam pendidikan tidak selalu meluaskan sebuah pengetahuan, tetapi juga sikapnya yang baik, kecerdasannya untuk mengekspresikan pikirannya, untuk mendengarkan dengan cermat, untuk membuat gerakan balik yang tepat, dengan martabat dan sesuai dengan kondisi untuk berperilaku.

Upaya dalam menguatkan nilai-nilai Pancasila di sekolah dasar dapat dilihat dari kegiatan yang dilakukan di sekolah itu sendiri. Kegiatan di sekolah dasar yang dapat mendukung untuk menguatkan nilai-nilai Pancasila dapat dijabarkan sebagai berikut.

1. Salat jamaah untuk kelas IV- VI

Puspitasari, Djunaedi, \& Putra (2012), berpendapat manusia selalu berusaha ingin mereplikasi dunia suci ke dunia nyata, dengan berusaha menerima kebaikan Tuhan melalui kegiatan religius. Karena itu, suatu wilayah secara material terkait dengan berbagai (Goh $\&$ van der Veer, 2016). Salah satunya wilayah sekolah dasar pada penelitian ini yakni terdapat penganut agama Islam dan Kristen. Salah satu kegiatan dari umat Islam adalah salat jamaah. Kegiatan ini dilakukan saat istirahat kedua tepat dengan waktu salat zuhur. Salat jamaah ini dilakukan lima hari dari enam hari pertemuan sekolah yakni Senin, Selasa, Rabu, Kamis, dan Sabtu. Pada kegiatan ini, guru laki-laki berperan sebagai imam, karena belum memungkinkan jika imam dari siswa itu sendiri. Mulai dari kegiatan wudu, guru mengawasi setiap siswa terutama kelas IV yang sekiranya belum menghafal gerakan wudhu dan mengondisikan siswa agar tidak membuat keributan di area musala. Sesuai dengan pendapat Necula (2014), tidak hanya pembelajarannya saja yang diwahyukan Tuhan untuk membelajarkan agama, namun juga perwakilan kelompok sosial yang dipercayai mampu mengajarkannya. Upaya yang dapat dilakukan untuk menguatkan nilai ketuhanan di sekolah dasar adalah menjalankan ajaran agama yang dianutnya, salah satunya dengan kegiatan salat berjamaah. Siswanto (2013) mengemukakan bahwa salat juga merupakan pelatihan pembinaan disiplin dan kontrol diri. Hal ini dapat membantu siswa dalam membiasakan 
bersikap disiplin pada setiap kegiatan di lingkungan sekolah dan masyarakat.

2. Pemilihan ketua kelas

Hasil observasi dan wawancara dengan guru kelas menunjukkan bahwa dalam proses pemilihan ketua kelas menggunakan voting pada kelas III-VI, sedangkan pada kelas I dan II menggunakan musyawarah mufakat dengan bimbingan dan arahan dari guru. Voting dapat memberdayakan individu untuk berpartisipasi dalam suatu hal (Vassil \& Weber, 2011). Proses voting dapat dilaksanakan walaupun tidak ada kegiatan tatap muka, yaitu dengan menggunakan $e$-voting. E-voting dikhususkan untuk mengakomodasi orang yang mobilitasnya kurang (Alvarez \& Hall, 2004), sementara pada kelas ini, tatap muka dan mobilitas dipastikan dapat dilakukan karena dilaksanakan pada hari efektif sekolah jadi tidak menggunakan $e$-voting.

Pachur dan Spaar (2015) mengemukakan bahwa musyawarah dapat dikendalikan secara sadar. Maka dari itu, guru kelas I dan II lebih memilih menggunakan strategi ini dalam pemilihan ketua kelas karena usia anak kelas I dan II masih sangat perlu dikendalikan. Walaupun dalam musyawarah mufakat, biasanya ada perbedaan pendapat satu sama lain (Betsch \& Iannello, 2009), akan tetapi perbedaan pendapat tersebut tidak timbul pada kelas ini. Hal ini dimungkinkan terjadi karena rasa kurang percaya diri dari siswa sendiri. Kegiatan ini dilakukan pada setiap awal semester. Kegiatan ini melatih siswa menanamkan nilai demokrasi di sekolah, karena ketua kelas tidak dipilih murni oleh guru melainkan mengikutsertakan siswa dalam pemilihan ketua kelas. Apabila siswa tidak diikutsertakan dalam pemilihan ketua kelas, berarti praktik demokrasi tidak berhasil. Demokrasi yang tidak berhasil dapat berujung bencana, seperti anarki dan kebodohan (Markopoulos \& Vanharanta, 2015). jadi, kegiatan pemilihan ketua kelas dengan mengikutsertakan siswanya merupakan upaya meminimalisasi kebodohan dan tindak anarki.

3. Berkerja sama dalam kelompok kecil

Kegiatan ini dilaksanakan saat pembelajaran berlangsung. Pembelajaran memuat hal penting yakni interaksi guru dengan siswa dan siswa dengan teman sebayanya (Course, 2014). Pada kegiatan kerja kelompok ini, interaksi yang terjadi cenderung lebih banyak antara siswa dengan teman sebayanya. Guru sebagai wali kelas, akan lebih memahami karakter tiap siswanya. Hal itu dituangkan dalam pembentukan kelompok yang beranggotakan tiga sampai empat anak. Guru beranggapan bahwa jika sebuah kelompok kecil memiliki anggota yang lebih dari empat, maka nantinya diskusi tidak akan berjalan secara efektif. Dalam sebuah kelompok, terdapat beberapa karakter siswa, mulai dari yang memiliki tingkat intelektual yang tinggi, sedang dan rendah. Hal ini ditujukan guru agar terjadi sebuah 'tutor sebaya' dalam kelompok tersebut. Gregory at al. (2011) mengemukakan cara belajar yang efektif adalah ketika seseorang mengajar orang lain sesamanya. Dengan begitu, siswa yang memiliki kemampuan intelektual yang tinggi akan mengajari siswa dalam kelompoknya yang memiliki kemampuan intelektual di bawahnya. Hal ini menanamkan nilai kemanusiaan pada diri siswa, yakni pengajaran kepada sesamanya dalam sebuah kelompok. Apabila tingkat penghargaan kepada manusia rendah, maka akan meningkatkan diferensiasi kelompok (Luke \& Maio, 2009). Maka, bekerja sama dalam kelompok kecil termasuk salah satu upaya untuk meminimalisasi diferensiasi sosial di kelas. Kegiatan lain yang menguatkan nilai kemanusiaan adalah kegiatan Pramuka yang diselenggarakan untuk siswa kelas IV-VI. Kegiatan itu dilakukan pada hari Jumat mulai pukul 13.3016.00 WIB. Pada kegiatan itu, siswa juga diajak untuk mengembangkan strategi tutor sebaya dalam penerapan tali-temali. Dengan begitu, siswa-siswa yang belum mampu, akan diajari oleh siswa yang sudah mumpuni dalam hal tali-temali.

4. Pembelajaran kepada seluruh siswa

Pembelajaran dilakukan mulai dari pukul 07.00 WIB sampai dengan pukul 10.00 WIB bagi siswa kelas I dan II, dan pukul 07-00 WIB sampai dengan pukul 12. 35 WIB untuk siswa kelas III-VI. Khusus untuk kelas VI, pada hari Senin dan Rabu terdapat tambahan pelajaran selama dua jam pelajaran. Pembelajaran merupakan aktivitas yang 
berorientasi pada proses (Luke \& Maio, 2009). Pembelajaran yang dilakukan guru tidak hanya sekadar mentransmisikan pengetahuan melainkan terdapat beberapa proses yang membuat siswa terlibat aktif dalam pembelajaran. Tidak hanya siswa yang perempuan atau laki-laki saja melainkan semua siswa yang ada di kelas berhak mengikuti pembelajaran dengan guru. Tindakan yang dilakukan guru ini merupakan penguatan nilai keadilan. Durrani (2018) mengemukakan, pendistribusian pendidikan yang tidak merata, akan menyebabkan konflik. Maka, untuk menghindari konflik, guru menanamkan nilai keadilan sejak dini.

5. Jumat bersih

Kegiatan ini dilakukan pada hari Jumat pagi setelah dilaksanakan senam dan sebelum pembelajaran dimulai. Kegiatan ini ditujukan kepada seluruh warga sekolah secara bersama-sama untuk membersihkan lingkungan sekolah. Lingkungan sekolah yang bersih menjadi ketertarikan untuk dipandang dan ditempati. Ali, Rostam, \& Awang (2014) mengatakan, lingkungan yang memiliki pemandangan menarik merupakan inspirasi bagi siswa, guru, karyawan sekolah dan orang tua. Agar sekolah tetap menjadi inspirasi dalam pelaksanaan pembelajaran, maka kita harus senantiasa menjaganya. Kegiatan ini menguatkan nilai persatuan antara siswa, guru, dan karyawan sekolah. Mereka bersatu untuk membersihkan lingkungan sekolah secara bersama-sama. Kegiatan lain yang menguatkan nilai persatuan adalah pelaksanaan upacara bendera pada hari Senin dan piket kelas pada tiap kelas. Upacara bendera mencerminkan persatuan antara siswa, guru, dan karyawan sekolah. Piket kelas mencerminkan persatuan antara siswa satu dengan yang lain untuk bersama-sama membersihkan kelas.

Keseluruhan kegiatan di atas, dilaksanakan dalam rangka menguatkan nilainilai Pancasila di sekolah dasar yang memiliki elemen warga sekolah yang heterogen. Kegiatan di atas melibatkan warga sekolah untuk ikut serta dalam kegiatan. Hal tersebut sesuai dengan pernyataan Mardikanto (2010) yang menyebutkan partisipasi adalah keikutsertaan seseorang atau sekelompok anggota masyarakat dalam suatu kegiatan. Wahab \& Sapriya (2011, hal. 9)) mengemukakan paradigma sistemis di dalam pendidikan kewarganegaraan terdapat tiga domain yakni domain akademis, domain kurikuler dan domain sosial kultural. Domain akademis adalah berbagai pemikiran tentang pendidikan kewarganegaraan yang berkembang di lingkungan komunitas keilmuan. Domain kurikuler adalah konsep praksis pendidikan kewarganegaraan dalam dunia pendidikan formal dan non formal. Domain sosial kultural adalah konsep dan praksis di lingkungan masyarakat. Berdasarkan pernyataan di atas penguatan nilai-nilai Pancasila di sekolah dasar termasuk dalam domain akademis (phsyco-paedagogial development).

Partisipasi sebagai warga sekolah dasar sangat berguna bagi keberhasilan program atau kegiatan yang dilaksanakan untuk mewujudkan kuatnya nilai Pncasila dalam kehidupan siswa. Upaya penguatan nilai-nilai Pancasila melalui partisipasi warga sekolah sangat berkaitan dengan perubahan sosial di lingkungan sekolah karena proses di dalamnya berkaitan dengan munculnya permasalahan sosial yang mengakibatkan melemahnya nilai-nilai Pancasila. Sekolah berupaya menguatkan nilai-nilai Pancasila dengan mengubah siswanya baik menjadi lebih baik dari sebelumnya berdasarkan Pancasila.

Rakhmat (2000, hal. 55), rekayasa sosial dilakukan karena munculnya problemproblem sosial. Problem sosial muncul karena adanya ketaksesuaian antara apa yang seharusnya, yang diinginkan (das sollen) dengan apa yang menjadi kenyataan (das sein). Misalnya dalam konteks studi ini, media sosial diharapkan akan dapat meningkatkan sikap pro sosial, akan tetapi ternyata apa yang diharapkan itu tidak terwujud, justru yang terjadi sebaliknya, muncul masalah adanya perilaku anti sosial. Dalam penelitian ini rekayasa sosial dijabarkan dengan mengidentifikasi indikator-indikator sebagai berikut: 1) sebab perubahan (cause of change); 2) sang pelaku perubahan (agent of change); 3) sasaran perubahan (target of change); 4) saluran perubahan (channel of 
change); dan 5) strategi perubahan (strategy of change).

Menurut teori rekayasa sosial terdapat beberapa indikator yang sesuai untuk menganalisis terkait upaya yang dilakukan sekolah untuk menguatkan nilai-nilai Pancasila. Analisis dalam penelitian ini dapat dijabarkan melalui sebagai berikut.

1. Sebab perubahan (cause of change)

Langkah pertama dalam rekayasa sosial yang harus dilakukan adalah menentukan penyebab perubahan yang menjadi permasalahan. Berkaitan dengan penelitian ini permasalahan yang akan direkayasa adalah mengupayakan untuk menguatkan nilai-nilai Pancasila di sekolah dasar dengan cara melakukan kegiatan intrakurikuler dan ekstrakurikuler, baik yang bersifat akademik maupun non akademik. Permasalahan yang muncul dan menjadi penyebab perubahan ini adalah perkembangan teknologi yang menimbulkan sikap anti sosial.

2. Sang pelaku perubahan (agent of change)

Agen perubahan adalah individu, kelompok atau organisasi yang berupaya untuk melakukan rekayasa sosial. Dalam rekayasa sosial penguatan nilai-nilai Pancasila di sekolah dasar adalah warga sekolah.

3. Sasaran perubahan (target of change)
Warga sekolah menjadi sasaran perubahan karena mereka berasal dari masyarakat heterogen yang sebelumnya kurang melakukan kegiatan-kegiatan sosial yang dapat menguatkan nilai-nilai Pancasila. Maka warga sekolah menjadi sasaran perubahan agar mereka dapat mengubah pola pikir untuk lebih meningkatkan sikap peduli sosial di antara sesama.

4. Saluran perubahan (channel of change)

Saluran perubahan yang akan dilalui dalam rekayasa sosial penguatan nilai-nilai Pancasila ini melalui kegiatan salat berjamaah, pemilihan ketua kelas, diskusi kelompok kecil, pramuka, pembelajaran di kelas, jumat bersih, upacara bendera dan piket kelas.

5. Strategi perubahan (strategy of change)

Strategi perubahan yang dilakukan oleh sekolah antara lain pengarahan, pelaksanaan dan pendampingan.

Setelah melalui proses dalam rekayasa sosial yang terakhir merupakan hasil dari perubahan sosial yakni perubahan sikap dari anti sosial menjadi peduli sosial yang nantinya dapat diterapkan dalam kehidupan sehari-hari sebagai masyarakat. Secara lebih jelas proses rekayasa sosial penguatan nilai-nilai Pancasila di sekolah dasar dapat dilihat pada skema berikut ini.

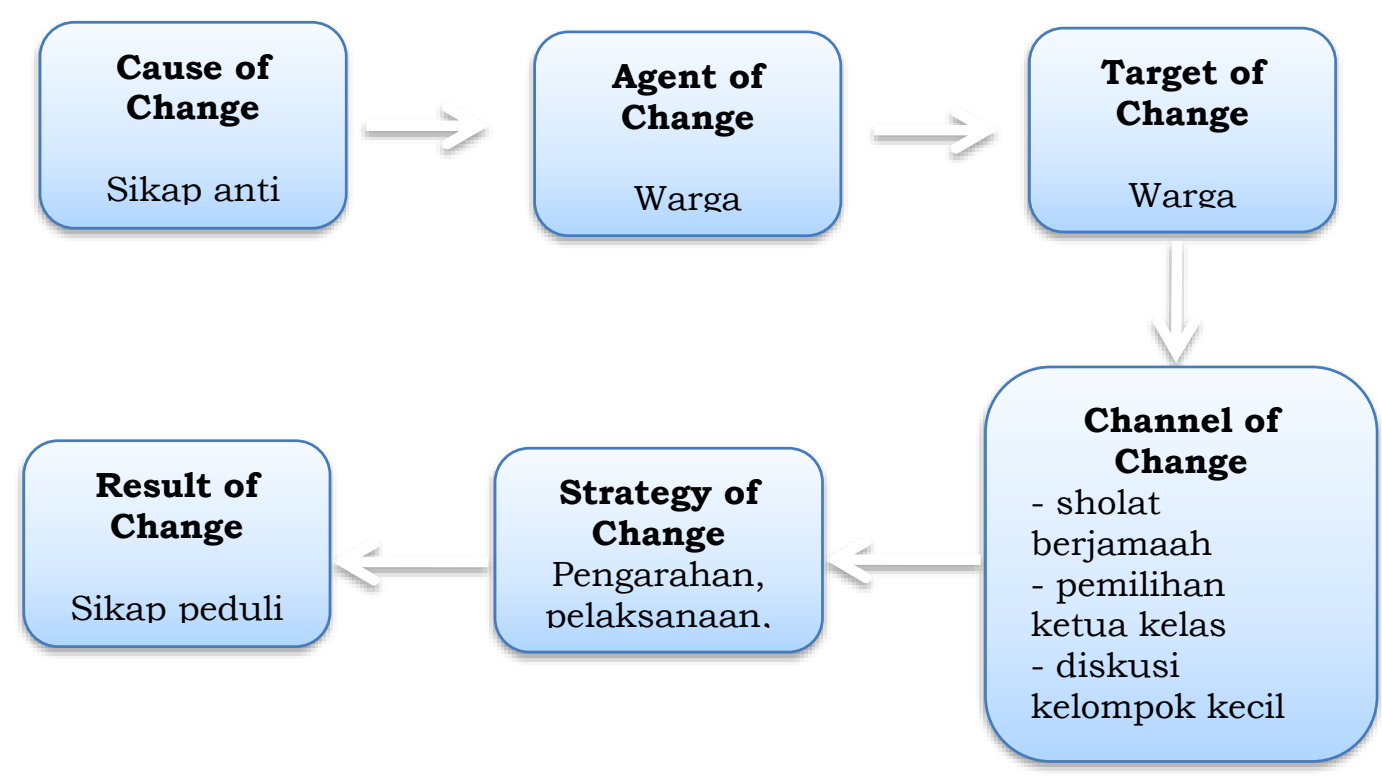

Gambar Skema Rekayasa Sosial Penguatan Nilai-Nilai Pancasila di Sekolah Dasar 
Pelaksanaan kegiatan penguatan nilainilai Pancasila mengalami beberapa kendala yang dapat mempengaruhi hasil dari kegiatan apabila tidak diatasi dengan serius. Hasil penelitian menunjukkan bahwa penguatan nilai-nilai Pancasila di sekolah dasar menemui kendala yaitu adanya beberapa anak yang sulit dinasihati dan beberapa kebiasaan anak diluar sekolah yang kurang baik terbawa ke sekolah. Sekolah mengatasi kendala tersebut dengan terus melakukan pembiasaan, bimbingan, dan pembinaan kepada anak.

\section{Ucapan Terima Kasih}

Pelaksanaan penguatan nilai-nilai Pancasila sekolah dasar sebagai upaya untuk mengimplementasikan nilai-nilai Pancasila di sekolah dilakukan melalui kegiatan: 1) salat berjamaah, 2) pemilihan ketua kelas, 3) diskusi kelompok kecil, 4) pramuka, 5) pembelajaran di kelas, 6) jumat bersih, 7) upacara bendera, dan 8) piket kelas. Pelaksanaan penguatan nilai-nilai Pancasila di sekolah dasar menemui kendala yaitu sikap anak yang sulit dinasihati dan memiliki kebiasaan di luar sekolah yang kurang baik. Hasil penelitian ini menegaskan sekaligus menguatkan teori rekayasa sosial bahwa perubahan sosial dapat terjadi melalui proses yang memenuhi indikator antara lain sebab perubahan, pelaku perubahan, target perubahan, saluran perubahan dan strategi perubahan. Selanjutnya hasil penelitian ini juga menguatkan Teori pendekatan pengembangan dalam pelaksanaan sosialisasi Pancasila bahwa upaya untuk mengembangkan pelaksanaan sosialisasi Pancasila dapat melalui 3 jalur yaitu Pengembangan pendidikan pembelajaran (psyco-pedagogial development), dan pengembangan sosial budaya (socio-cultural development). Temuan penelitian ini menunjukkan bahwa pengembangan pelaksanaan sosialisasi Pancasila di sekolah dasar termasuk dalam kategori pendekatan jalur pengembangan pendidikan pembelajaran (psyco-pedagogial development). Perubahan yang terjadi dari yang sebelumnya anti sosial menjadi memiliki sikap peduli sosial yang akhirnya dapat memberikan hasil yang baik untuk menguatkan nilai-nilai Pancasila.

\section{Referensi}

Al-Rahmi, W. M., \& Zeki, A. M. (2017). A model of using social media for collaborative learning to enhance learners' performance on learning. Journal of King Saud UniversityComputer and Information Sciences, 29(4), 526-535.

Ali, S. M., Rostam, K., \& Awang, A. H. (2014). School landscape environments in assisting the learning process and in appreciating the natural environment. ASEAN-Turkey ASLI (Annual Serial Landmark International) Conference on Quality of Life-ABRA International Conference on Quality of Life, 202(December 2014), 189-198. https://doi.org/10.1016/j.sbspro.2015.08 .222

Aljawiy, A. Y., \& Muklason, A. (2011). Jejaring sosial dan dampak bagi penggunanya. TEKNOLOGI: Jurnal Ilmiah Sistem Informasi, 1(1), 1-7.

Alvarez, M. R., \& Hall, T. E. (2004). Point, click, and vote: The future of Internet elections. Washington, D.C: The Brookings Institution.

Amedie, J. (2015). The impact of social media on society. Advanced Writing: Pop Culture Intersections. 2. Diambil dari $\mathrm{http}: / /$ scholarcommons.scu.edu/engl_17 6/2\%0AThis

Betsch, C., \& Iannello, P. (2009). Measuring individual differences in intuitive and deliberate decision-making styles. In A. Glöckner \& G. Witteman (Ed.), Tracing intuition: Recent methods in measuring intuitive and deliberate processes in decision making (hal. 251). London: Psychology Press.

Budimansyah, D. (2010). Penguatan pendidikan kewarganegaraan untuk membangun karakter bangsa. Bandung: Widya Aksara Press.

Course, S. (2014). ELT Students' use of 
teacher questions in peer teaching. In 14th International Language, Literature and Stylistics Symposium ELT (Vol. 158, hal. 331-336). Procedia - Social and Behavioral Sciences, Elsevier B.V. https://doi.org/10.1016/j.sbspro.2014.12 .096

Durrani, N., \& Halai, A. (2018). Dynamics of gender justice, conflict and social cohesion: Analysing educational reforms in Pakistan. International Journal of Educational Development, 61(January), 27-39.

https://doi.org/10.1016/j.ijedudev.2017. 11.010

Ertmer, P. A., Newby, T. J., Liu, W., Tomory, A., Yu, J. H., \& Lee, Y. M. (2011). Students' confidence and perceived value for participating in cross-cultural wiki-based collaborations. Educational Technology Research and Development, 59(2), 213-228.

Goh, D. P., \& van der Veer, P. (2016). Introduction: The sacred and the urban in Asia. International Sociology, 31(4), 367-374. https://doi.org/10.1177/0268580916643 088

Gregory, A., Walker, I., Mclaughlin, K., \& Peets, A. D. (2011). Both preparing to teach and teaching positively impact learning outcomes for peer teachers. Medical Teacher, 33(8), e417-e422. https://doi.org/10.3109/0142159X.2011. 586747

Junco, R., Heibergert, G., \& Loken, E. (2013). An analytycal method for calculating the natural frequency of retaining walls. International Journal of Civil Engineering, $\quad 11(1 \quad$ B $), \quad 1-9$. https://doi.org/10.1111/j.13652729.2010.00387.x

Kozhanova, M. B., Svechnikova, N. V, \& Guliya, N. (2017). Psycho-pedagogical conditions of professional culture development of a university professor. INTERNATIONAL ELECTRONIC JOURNAL OF MATHEMATICS EDUCATION, 12(1), 15-23.
Kus, Z. (2015). Participation status of primary school students. Procedia - Social and Behavioral Sciences, 177(July 2014), 190-196.

https://doi.org/10.1016/j.sbspro.2015.02 .381

Larusson, J. A., \& Alterman, R. (2009). Wikis to support the "collaborative" part of collaborative learning. International Journal of Computer-Supported Collaborative Learning, 4(4), 371-402.

Luke, M. A., \& Maio, G. R. (2009). Oh the humanity! Humanity-esteem and its social importance. Journal of Research in Personality, 43(4), 586-601. https://doi.org/10.1016/j.jrp.2009.03.00 1

Mardikanto, T. (2010). Komunikasi pembangunan: acuan bagi akademisi, praktisi, dan peminat komunikasi pembangunan. Surakarta: Sebelas Maret University Press.

Mares, M. L., Sivakumar, G., \& Stephenson, L. (2015). From meta to micro: Examining the effectiveness of educational TV. American Behavioral Scientist, 59(14), 1822-1846. https://doi.org/10.1177/0002764215596 555

Markopoulos, E., \& Vanharanta, H. (2015). The company democracy model for the development of intellectual human capitalism for shared value. In 6th International Conference on Applied Human Factors and Ergonomics (Vol. 3, hal. 603-610). Procedia - Manufacturin, Elsevier. https://doi.org/10.1016/j.promfg.2015.0 7.277

Miles, M. B., \& Huberman, A. M. (1992). Analisis data kualitatif. Jakarta: Universitas Indonesia Press.

Necula, M. I. (2014). Religious Values Left Outside the Scope of Penal Protection. Procedia - Social and Behavioral Sciences, 149, 634-638. https://doi.org/10.1016/j.sbspro.2014.08 .240 
Novak, E., Razzouk, R., \& Johnson, T. E. (2012). The educational use of social annotation tools in higher education: A literature review. The Internet and Higher Education, 15(1), 39-49.

Pachur, T., \& Spaar, M. (2015). Domainspecific preferences for intuition and deliberation in decision making. Journal of Applied Research in Memory and Cognition, 4(3), 303-311.

Puspitasari, P., Djunaedi, S. A., \& Putra, H. S. A. (2012). Ritual and space structure: Pilgrimage and space use in historical urban kampung context of Luar Batang (Jakarta, Indonesia). In ASEAN Conference on Environment-Behaviour Studies (Vol. 36, hal. 350-360). Bandung: Procedia - Social and Behavioral Sciences 36. https://doi.org/10.1016/j.sbspro.2012.03 .039

Rakhmat, J. (2000). Rekayasa sosial: Reformasi, revolusi, atau manusia besar? Bandung: Remaja Rosdakarya.

Setiawan, W. (2017). Era digital dan tantangannya. In Seminar Nasional Pendidikan 2017 (hal. 1-9). Sukabumi: UMMI.

Siswanto, F. Z. (2013). Hubungan antara kedisiplinan melaksanakan sholat wajib dengan prokrastinasi akademik pada mahasiswa di Fakultas Farmasi Universitas Ahmad Dahlan. EMPATHY Jurnal Fakultas Psikologi, 2(1).

Vassil, K., \& Weber, T. (2011). A bottleneck model of e-voting: Why technology fails to boost turnout. New Media and Society, 13(8), 1336-1354. https://doi.org/10.1177/1461444811405 807

Wahab, A. A., \& Sapriya. (2011). Teori dan landasan pendidikan kewarganegaraan. Bandung: Alfabeta.

Yudhanegara, H. F. (2015). Pancasila sebagai filter pengaruh globalisasi terhadap nilainilai nasionalisme. Cendekia - Jurnal Ilmu Administrasi Negara, VIII(2), 165180. 